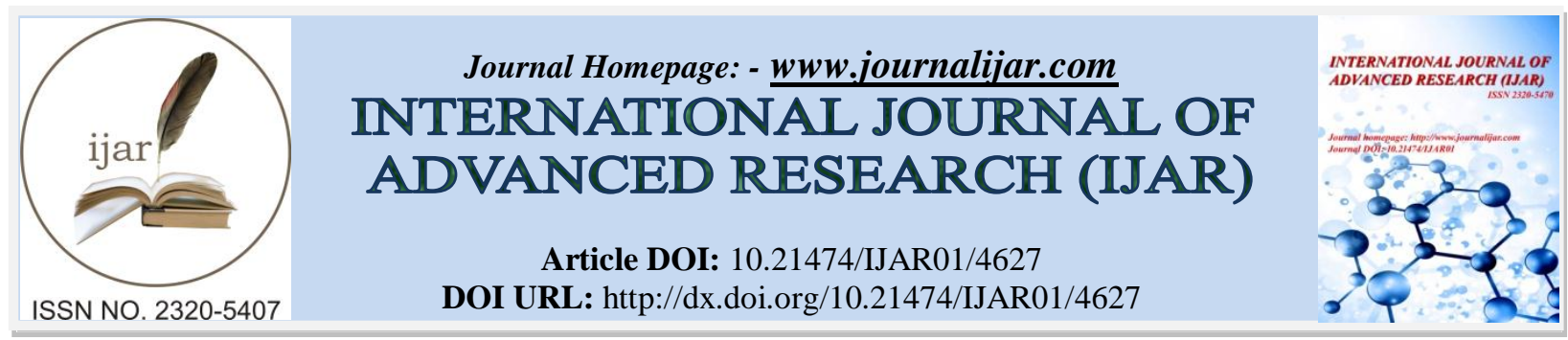

RESEARCH ARTICLE

\title{
DERIVATIVE MICELLAR SPECTRAL ANALYSIS AND BIOLOGICAL EVOLUTION OF PR (III)-8HQ COMPLEXES.
}

\author{
S. N. Jatolia ${ }^{1}$, Ravi Sethi ${ }^{2}$, Kailash Chand ${ }^{3}$ and N. Bhojak ${ }^{1}$. \\ 1. GCRC, P.G. Department of Chemistry, Govt Dungar College (NAAC 'A' Grade), Bikaner Rajasthan, India. \\ 2. Govt.food Testing Laboratory,Udaipur, Rajasthan, India. \\ 3. SPC Govt. College Ajmer MDS University, Ajmer, India.
}

\section{Manuscript Info}

Manuscript History

Received: 27 April 2017

Final Accepted: 29 May 2017

Published: June 2017

Key words:-

8-Hydroxy quinoline, Pr (III) ion and bonding parameters.

\begin{abstract}
Optical spectral investigations in micellar medium have been carried out for derivative spectra of $\operatorname{Pr}(\mathrm{III})$-quinoline systems. The $4 f-4 f$ transition spectra yield sharp bands which were analyzed individually by Gaussian curve analysis. Various energies and intensities of all the transitions were calculated using Judd-Ofelt relation and are perfectly matches with observed value. Low rms deviation confirms the formation of complex. Lande spin orbit coupling $\left(\xi_{4 f}\right)$, nephelauxetic ratio $(\beta)$, bonding parameter $\left(b^{1 / 2}\right)$, Percent covalency $(\delta)$, have been computed on computer using partial multiple regression analysis. The Judd-Ofelt intensity $\left(T_{2}, T_{4}, T_{6}\right)$ parameters also have been evaluated by Using a least-squares fit method. From the magnitude of the bonding parameter $(\delta)$.which suggests covalency in complex. By applying the Judd-Ofelt theory a good correlation has been established between the experimental and calculated data.

Biological evolutions of these systems on three microorganisms have also been reported first time. A trend for antibacterial studies has been observed.
\end{abstract}

Copy Right, IJAR, 2017,. All rights reserved.

\section{Introduction:-}

It is Interesting part of lanthanide chemistry that the efficient shielding of the $4 \mathrm{f}$ shells by closed $5 \mathrm{~s}^{2}$ and $5 \mathrm{p}^{6}$ shells leads the trivalent lanthanide ions to exhibit unique spectroscopic properties. Since the $4 \mathrm{f}$ lie deep in the nucleus core, the ligand environment only weakly affects the lanthanide electron cloud which is small in magnitude. The line width of the $4 \mathrm{f}-4 \mathrm{f}$ bands is considerably smaller than that observed for transition metal ions and the peak position of the spectral band reveals a part of $4 \mathrm{fn}$ configuration.(1-4) In the present study, the properties of lanthanides are mainly focused on the comparative absorption spectrometry and the corresponding changes in oscillator strength of different $4 \mathrm{f}-4 \mathrm{f}$ transition spectra as probe(5-6) in understanding the characteristics of $\operatorname{Pr}(\mathrm{III})$ ion and $\operatorname{Pr}(\mathrm{III})$ with 8Hydroxy quinoline in alcoholic (Et-OH) and Micellar medium (viz: TX-100, HTAB and SDS) have been calculated.

\section{Material and Method:-}

Praseodymium chloride of $99.9 \%$ and ligand was procured from Ms. Indian Earth limited. The solvents used in doped system are Ethyl Alcohol (AR 99.9\%, Jiangsu-Hliaxi International Trade Co. Ltd., Made in China) and Triton-X-100(100 CMC solution, Loba Chemia Pvt.Ltd., Mumbai, India).The saturated solution of ligand and metals $\operatorname{Pr}(\mathrm{III})$ ion $0.05 \mathrm{M}$ were prepared in different solvents (Triton X-100 of $100 \mathrm{CMC}\left(1.8 \times 10^{-2} \mathrm{M}\right.$, Sodium 
Dodecyl sulphate, (SDS) of 75 CMC (0.05 M), and Hexadecyl Trimethyl Ammonium Bromide, (HTAB) of 100 CMC $\left(9.2 \times 10^{-2} \mathrm{M}\right)$ is used for preparing saturated solution of ligand and metal. The UV-visible (normal and derivative) spectra from $400 \mathrm{~nm}$ to $600 \mathrm{~nm}$ were recorded on (5704-SS) UV Visible Double Beam spectrophotometer at room temperature in 1:3 ratio (Metal: Ligand) at Green chemistry research center (GCRC) Bikaner.

\section{Oscillator strength:-}

The intensity of a band is measured in term of Oscillator strength which is expressed in term of molar extinction coefficient $(\epsilon)$ and the energy of transition in term of wave number $(v)$ by the following equation

$$
\begin{aligned}
& \mathrm{P}=4.315 \times 10^{-9} \int \varepsilon \mathrm{d} v- \\
& \mathrm{P}_{\mathrm{obs}} \approx 4.6 \times 10^{-9} \times \varepsilon_{\max } \Delta v^{1 / 2}
\end{aligned}
$$

According to Judd-Ofelt theory, the oscillator strength for transition of energy can be calculated by using JuddOfelt parameters (7-8) $\left(\mathrm{T}_{2}, \mathrm{~T}_{4}\right.$ and $\left.\mathrm{T}_{6}\right)$ with the help of formula-

$$
\begin{aligned}
& \mathrm{P}_{\mathrm{cal}}=\mathrm{T}_{2} v\left[\mathrm{U}^{(2)}\right]^{2}+\mathrm{T}_{4} v\left[\mathrm{U}^{(4)}\right]^{2}+\mathrm{T}_{6} v\left[\mathrm{U}^{(6)}\right]^{2}-----------(3) \\
& \text { Where }\left[\mathrm{U}^{(2)}\right]^{2},\left[\mathrm{U}^{(4)}\right]^{2},\left[\mathrm{U}^{(6)}\right]^{2} \text { are matrix elements (13-14). }
\end{aligned}
$$

Slater- Condon $\left(\mathbf{F}_{2}, \mathbf{F}_{4}, \& \mathbf{F}_{6}\right)$ and Lande parameter $\left(\zeta_{4 f}\right)$ :-

The values of Slater-Condon parameters $\left(\mathrm{F}_{\mathrm{k}}\right)$ and Lande para-meters $\left(\zeta_{4 \mathrm{f}}\right)$ are then evaluated using following equations-

$$
\begin{aligned}
& \mathrm{F}_{\mathrm{k}}=\mathrm{F}_{\mathrm{k}}^{\mathrm{o}}+\Delta \mathrm{F}_{\mathrm{k}}
\end{aligned}
$$

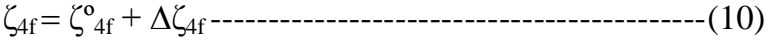

Where, $\Delta \mathrm{F}_{\mathrm{k}}<<\mathrm{F}_{\mathrm{k}}^{\mathrm{o}}, \Delta \zeta_{4 \mathrm{f}}<<\zeta_{4 \mathrm{f}}^{\mathrm{o}}$ and $\mathrm{F}_{\mathrm{k}}^{\mathrm{o}}$ and $\zeta_{4 \mathrm{f}}^{\mathrm{o}}$ are the zero -order values of Slater-Condon and spin-orbit interaction parameters as reported by Wong (16).

Racah Parameters or Energy parameters $\left(E^{1}, E^{2}\right.$ and $\left.E^{3}\right)$ :-

The Slater- Condon $F_{2}, F_{4}, \& F_{6}$ and Lande parameter or Spin-Orbit Coupling Constant $\left(\zeta_{4 f}\right)$ may be evaluated by expressing energy as Taylor series expansion may be used to express the energy of $j^{\text {th }}$ electronic energy level and The Racah parameters $\mathrm{E}^{\mathrm{k}}(\mathrm{k}=1,2$, and 3$)$ are related to $\mathrm{F}_{\mathrm{k}}(\mathrm{k}=2$,4and6) parameters by the following relations -

$$
\begin{aligned}
& \mathrm{E}^{1}=(1 / 9)\left(70 \mathrm{~F}_{2}+231 \mathrm{~F}_{4}+2002 \mathrm{~F}_{6}\right) \\
& \mathrm{E}^{2}=(1 / 9)\left(\mathrm{F}_{2}-3 \mathrm{~F}_{4}+7 \mathrm{~F}_{6}\right) \\
& \mathrm{E}^{3}=(1 / 3)\left(5 \mathrm{~F}_{2}+6 \mathrm{~F}_{4}-91 \mathrm{~F}_{6}\right) \text {--------------- (13) }
\end{aligned}
$$

By assuming wave functions to be hydrogenic as $\mathrm{E}^{\mathrm{K}} \mathrm{s}$ (racah parameters) are the linear combination of $\mathrm{F}_{\mathrm{K}}$ 's, they may be calculated by using the following relation the Racah parameters reduces to in case of $\operatorname{Pr}^{+3}$ complexes which have been evaluated using these equations.

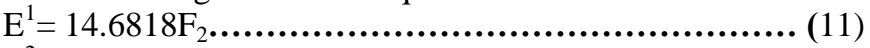

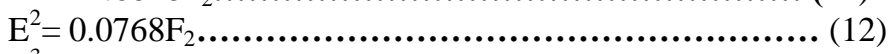

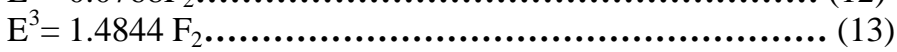

The $\mathrm{F}_{2}$ values thus obtained for $\operatorname{Pr}(\mathrm{III})-8 \mathrm{HQ}$ in different medium alcoholic (301.12) TX- 100 $\operatorname{HTAB}(303.40)$, SDS (302.44) are in close agreement with the values derived from the Racah parameters $\left(\mathrm{E}^{1}, \mathrm{E}^{2}\right.$, $\mathrm{E}^{3}$ ) by the relation (Table-8)

\section{Bonding Parameters:-}

These parameters consist of Nephelauxetic ratio $(\beta)$, bonding parameter $\left(b^{1 / 2}\right)$, Sinha's Covalency Parameters $(\delta \%)$ and Covalency angular overlap Parameter $(\eta)(16-18)$.

\section{Nephelauxetic Ratio ( $\beta$ ):-}

The effect of complexation on the free ion is the red shift of the electronic transition. This effect $\quad$ can be represented in terms of Nephelauxetic ratio $(\beta)$ as follows -

$\beta=v_{c} / v_{f}$

Where, $v_{\mathrm{c}}$ and $v_{\mathrm{f}}$ are wave numbers of $\mathrm{f}-\mathrm{f}$ transition for spectra of complex and free ion respectively. 
Bonding parameter $\left(b^{1 / 2}\right)$ :-

The Nephelauxetic ratio value can be used to calculate the bonding parameter, from the relation given as $b^{1 / 2}=[1 / 2(1-\beta)]^{1 / 2}$

Positive value of bonding parameter $\left(\mathrm{b}^{1 / 2}\right)$ indicates covalent character in metal-ligand bond while negative value shows ionic character in metal-ligand interaction.

Sinha's Covalency Parameters $(\delta \%)$ :-

Percentage covalent character in metal ligand bond can be expressed by

Sinha's covalency parameter $(\delta \%)$

$\delta=[1-\beta / \beta]$ X 100

\section{Covalency angular overlap parameter $(\eta)$ :-}

Covalency angular overlap parameter $(\eta)$ represents extent of Overlapping Between metal ion orbital and ligand orbital

$$
\eta=\left[1-\beta^{1 / 2} / \beta^{1 / 2}\right]
$$

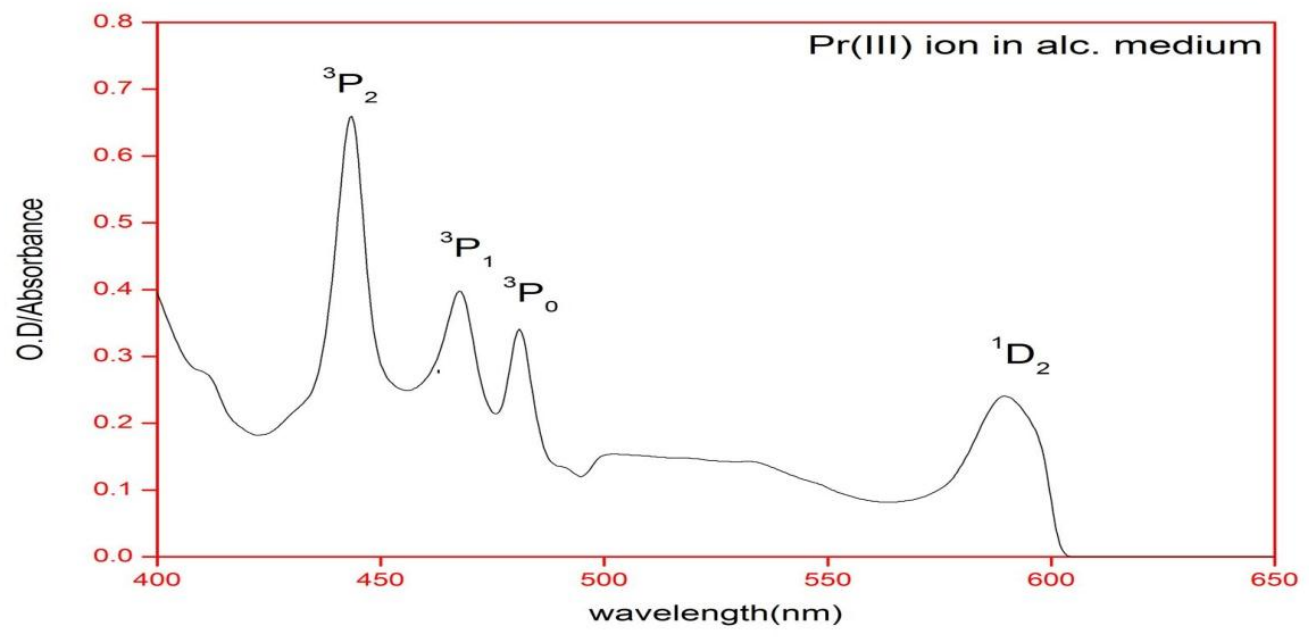

Fig 1:- Normal Electronic Spectrum Of Pr(III)-8HQ In Alcoholic Medium
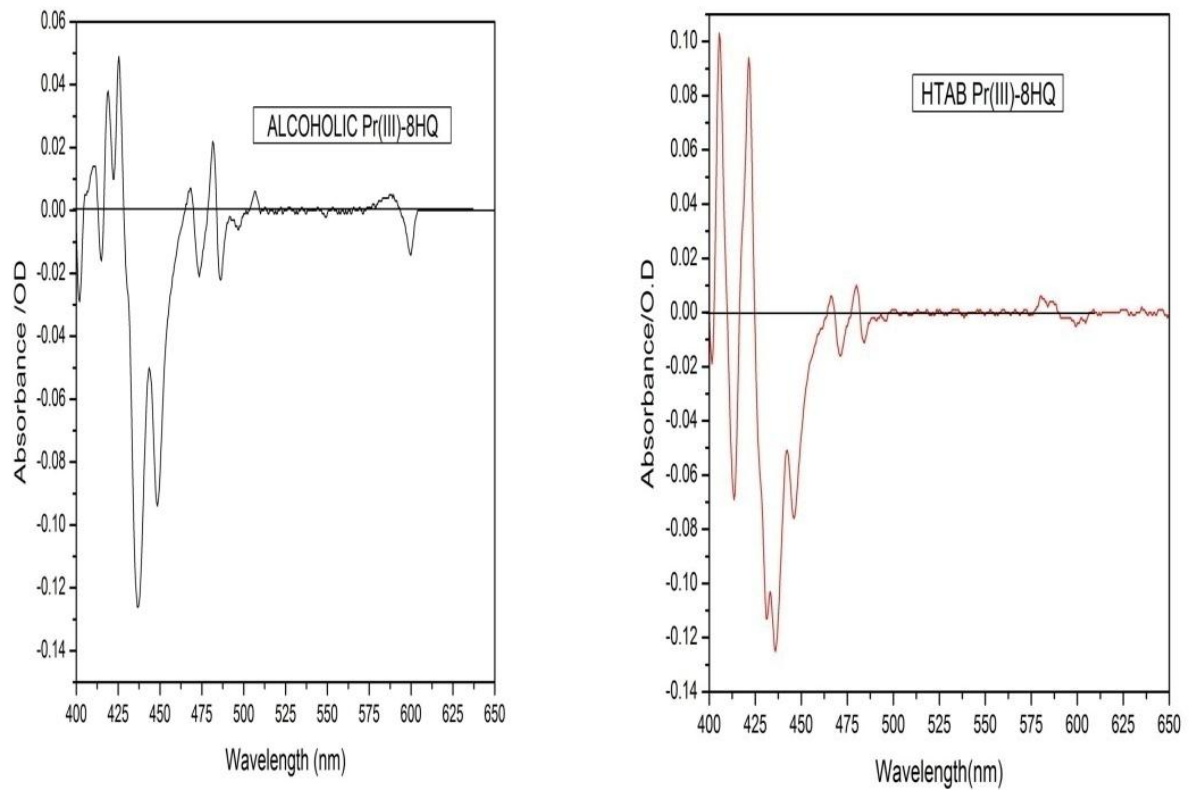

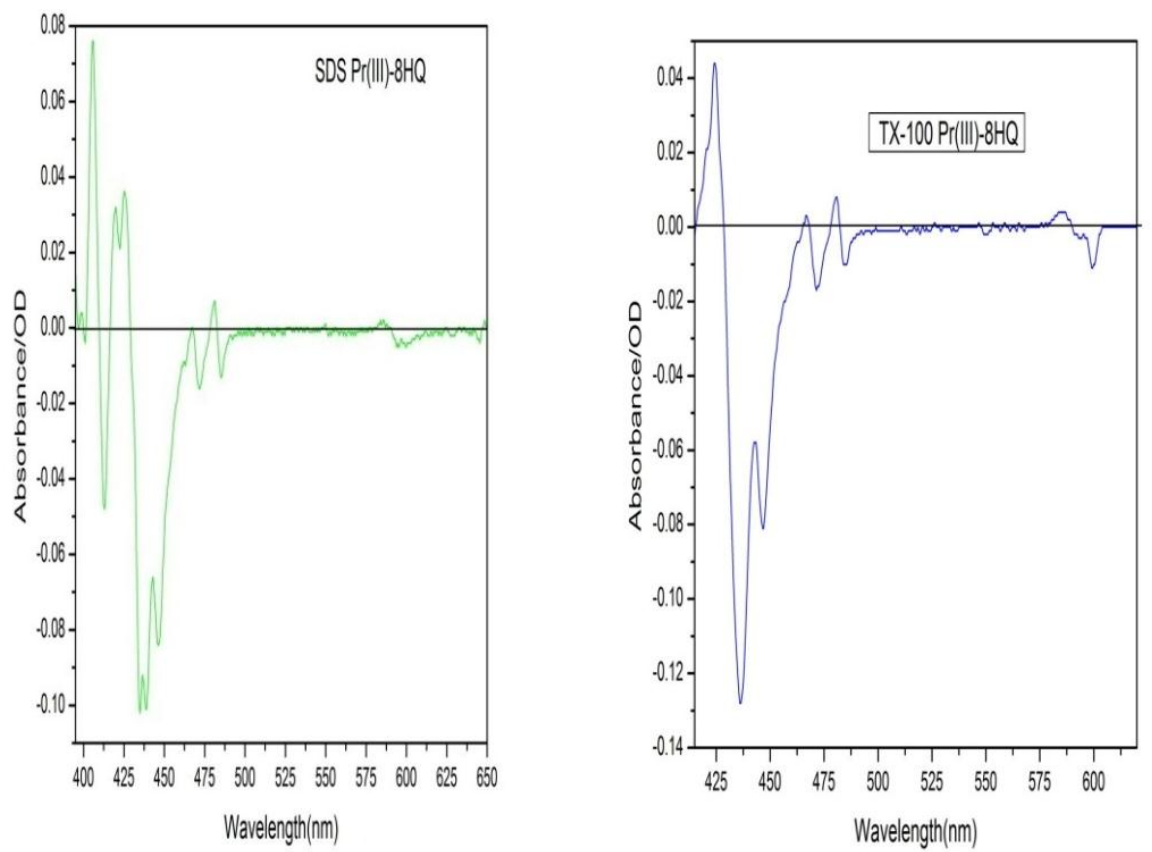

Fig.2:-Derivative Electronic Spectrum Of Pr (III)-8HQ in Different Solvent

Table 1:- Computed values of judd Ofelt Parameter $\left(\mathrm{T}_{\lambda}\right)$,Symmetry Parameter $\left(\mathrm{T}_{4} / \mathrm{T}_{2}\right)$, and Coordination Parameter $\left(\mathrm{T}_{4} / \mathrm{T}_{6}\right)$ of $\operatorname{Pr}(\mathrm{III})-8 \mathrm{HQ}$ Complex in alcoholic and micellar medium.

Coordination Parameter $\left(\mathrm{T}_{4} / \mathrm{T}_{6}\right)$ of $\operatorname{Pr}(\mathrm{III})-8 \mathrm{HQ}$ Complex in alcoholic and micellar medium

\begin{tabular}{|l|l|l|l|l|l|}
\hline S.N. & \multirow{2}{*}{ Parameter } & Pr(III)-8HQ & Pr(III)-8HQ & Pr(III)-8HQ & Pr(III)-8HQ \\
\cline { 3 - 6 } & & $($ EtOH) & $($ TX-100) & (HTAB) & (SDS) \\
\hline 1 & T2 $\times 10^{9}$ & 123.815 & -0.970 & -1.146 & -1.128 \\
\hline 2 & T4 $\times 10^{9}$ & 14.437 & 0.031 & 0.037 & 0.036 \\
\hline 3 & T6 109 & 22.766 & 16.002 & 18.897 & 18.603 \\
\hline 4 & T4/T6 & 0.634 & 0.002 & 0.002 & 0.002 \\
\hline 5 & T4/T2 & 0.117 & -0.032 & -0.032 & -0.032 \\
\hline
\end{tabular}

Table 2:- Observed and calculated values of Oscillator strength $\left(\mathrm{Px}_{10} 0^{6}\right)$ of various Absorption transitions of Pr(III)-8HQ Complex in organic and Micellar medium.

\begin{tabular}{|c|c|c|c|c|c|c|c|c|c|}
\hline \multirow{2}{*}{\multicolumn{2}{|c|}{ COMPLEX }} & \multicolumn{2}{|c|}{$\operatorname{Pr}(\mathrm{III})-8 \mathrm{HQ}$} & \multirow{2}{*}{\multicolumn{2}{|c|}{$\operatorname{Pr}(\mathrm{III})-8 \mathrm{HQ}$}} & \multirow{2}{*}{\multicolumn{2}{|c|}{ Pr(III)-8HQ }} & \multicolumn{2}{|c|}{$\begin{array}{l}\operatorname{Pr}(\mathrm{III})-8 \mathrm{HQ} \\
\end{array}$} \\
\hline & & \multicolumn{2}{|c|}{ (EtOH) } & (TX-100) & & (HTAB) & & \multicolumn{2}{|c|}{ (SDS) } \\
\hline S.N. & Energy Levels & $P_{\text {obs }} \times 10^{6}$ & $P_{\text {cal }} \times 10^{6}$ & $P_{\text {obs }} \times 10^{6}$ & $P_{\mathrm{cal}} \times 10^{6}$ & $P_{o b s} \times 10^{6}$ & $\mathbf{P}_{\mathrm{cal}} \mathbf{x} 10^{6}$ & $P_{\text {obs }} \times 10^{6}$ & $P_{\mathrm{cal}} \times 10^{6}$ \\
\hline 1 & ${ }^{3} \mathrm{H}_{4} \rightarrow{ }^{3} \mathrm{P}_{2}$ & 29.371 & 193.952 & 51.401 & 50.864 & 66.844 & 60.684 & 65.296 & 59.064 \\
\hline 2 & ${ }^{3} \mathrm{H}_{4} \rightarrow{ }^{3} \mathrm{P}_{1}$ & 5.510 & 11.450 & 0.311 & 1.235 & 10.533 & 0.148 & 8.948 & 0.144 \\
\hline 3 & ${ }^{3} \mathrm{H}_{4} \rightarrow{ }^{3} \mathrm{P}_{0}$ & 2.391 & 58.218 & 2.072 & 0.125 & 1.902 & 1.495 & 3.282 & 0.146 \\
\hline 4 & ${ }^{3} \mathrm{H}_{4} \rightarrow{ }^{1} \mathrm{D}_{2}$ & 3.062 & 40.867 & 3.746 & 19.373 & 5.418 & 23.113 & 2.539 & 22.495 \\
\hline 5 & r.m.s. $(\sigma)$ & \multicolumn{2}{|l|}{93.757} & \multicolumn{2}{|l|}{7.879} & \multicolumn{2}{|l|}{10.747} & \multicolumn{2}{|l|}{11.450} \\
\hline & dev. $( \pm)$ & & & & \\
\hline
\end{tabular}

Table 3:- Observed and calculated value of Energy $\left(\mathrm{cm}^{-1}\right)$ of various energy level of $\operatorname{Pr}(\mathrm{III})-8 \mathrm{HQ}$ Complexe in Organic and Micellar medium.

\begin{tabular}{|c|c|c|c|c|c|c|c|c|c|}
\hline \multicolumn{2}{|c|}{ COMPLEX } & \multirow{2}{*}{\multicolumn{2}{|c|}{$\begin{array}{l}\operatorname{Pr}(\text { III)-8HQ } \\
\text { (EtOH) }\end{array}$}} & \multirow{2}{*}{\multicolumn{2}{|c|}{$\begin{array}{l}\text { Pr(III)-8HQ } \\
\text { (TX-100) }\end{array}$}} & \multirow{2}{*}{\multicolumn{2}{|c|}{$\begin{array}{l}\text { Pr(III)-8HQ } \\
\text { (HTAB) }\end{array}$}} & \multirow{2}{*}{\multicolumn{2}{|c|}{$\begin{array}{l}\text { Pr(III)-8HQ } \\
\text { (SDS) }\end{array}$}} \\
\hline & & & & & & & & & \\
\hline S.N. & LEVELS & $\mathbf{E}_{\mathrm{cal}}$ & $\mathbf{E}_{\text {obs }}$ & $\mathbf{E}_{\text {cal }}$ & $\mathbf{E}_{\text {obs }}$ & $\mathbf{E}_{\text {cal }}$ & $\mathbf{E}_{\text {obs }}$ & $\mathbf{E}_{\text {cal }}$ & $\mathbf{E}_{\text {obs }}$ \\
\hline 1 & ${ }^{3} \mathrm{P}_{2}$ & 23334.7 & 23337.2 & 23334.9 & 23337.2 & 23553.9 & 23557.1 & 23307.8 & 23310.0 \\
\hline 2 & ${ }^{3} \mathrm{P}_{1}$ & 21279.4 & 21276.6 & 21347.3 & 21344.7 & 21325.1 & 21321.9 & 21370.0 & 21367.5 \\
\hline 3 & ${ }^{3} \mathrm{P}_{0}$ & 20661.5 & 20661.2 & 20747.3 & 20746.9 & 20747.8 & 20746.9 & 20725.7 & 20725.4 \\
\hline 4 & ${ }^{1} D_{2}$ & 16863.0 & 16863.4 & 16963.1 & 16963.5 & 16977.4 & 16977.9 & 16948.8 & 16949.2 \\
\hline
\end{tabular}


Table 4:- Computed values of Bonding parameters : Nephelauxetic ratio ( $\beta$ ), Bonding $\left(b^{1 / 2}\right)$,Sinha Covalency $(\delta \%)$ and Covalency-Angular Overlap $(\eta)$ Parameters of $\operatorname{Pr}(\mathrm{III})-8 \mathrm{HQ}$ Complex in (SDS) micellar medium

\begin{tabular}{|l|l|l|l|l|l|}
\hline Energy Levels & $\mathbf{v}_{\mathbf{c}}\left(\mathbf{c m}^{-\mathbf{1}}\right)$ Obs & $\boldsymbol{\beta}$ & $\mathbf{b}^{\mathbf{1 / 2}}$ & $\boldsymbol{\delta} \%$ & $\boldsymbol{\eta}$ \\
\hline${ }^{\mathbf{3}} \mathbf{P}_{\mathbf{2}}$ & 23310.02 & 1.036 & 0.134 & -3.487 & -0.018 \\
\hline${ }^{3} \mathbf{P}_{\mathbf{1}}$ & 21367.52 & 1.002 & 0.033 & -0.213 & -0.001 \\
\hline${ }^{\mathbf{3}} \mathbf{P}_{\mathbf{0}}$ & 20725.39 & 1.000 & 0.000 & 0.000 & 0.000 \\
\hline${ }^{1} \mathbf{D}_{\mathbf{2}}$ & 16949.15 & 1.003 & 0.036 & -0.254 & -0.001 \\
\hline
\end{tabular}

Table 5:- Computed values of Bonding parameters in (T X-100) micellar medium

\begin{tabular}{|l|l|l|l|l|l|}
\hline Energy Levels & $\boldsymbol{V}_{\mathbf{c}}\left(\mathbf{c m}^{-\mathbf{1}}\right) \mathbf{O b s}$ & $\boldsymbol{\beta}$ & $\mathbf{b}^{\mathbf{1 / 2}}$ & $\mathbf{\delta} \%$ & $\boldsymbol{\eta}$ \\
\hline${ }^{3} \mathbf{P}_{\mathbf{2}}$ & 23337.22 & 1.037 & 0.137 & -3.600 & -0.018 \\
\hline${ }^{\mathbf{3}} \mathbf{P}_{\mathbf{1}}$ & 21344.72 & 1.001 & 0.023 & -0.107 & -0.001 \\
\hline${ }^{\mathbf{3}} \mathbf{P}_{\mathbf{0}}$ & 20746.89 & 1.001 & 0.023 & -0.104 & -0.001 \\
\hline${ }^{1} \mathbf{D}_{\mathbf{2}}$ & 16977.93 & 1.001 & 0.021 & -0.085 & 0.000 \\
\hline
\end{tabular}

Table 6:- Computed values of Bonding parameters in (HTAB) micellar medium

\begin{tabular}{|l|l|l|l|l|l|}
\hline Energy Levels & $\boldsymbol{v}_{\mathbf{c}}\left(\mathbf{c m}^{-\mathbf{1}}\right)$ Obs & $\boldsymbol{\beta}$ & $\mathbf{b}^{\mathbf{1 / 2}}$ & $\mathbf{\delta} \%$ & $\boldsymbol{\eta}$ \\
\hline${ }^{\mathbf{3}} \mathbf{P}_{\mathbf{2}}$ & 23557.13 & 1.045 & 0.150 & -4.284 & -0.022 \\
\hline${ }^{3} \mathbf{P}_{\mathbf{1}}$ & 21321.96 & 0.997 & 0.040 & 0.321 & 0.002 \\
\hline${ }^{\mathbf{3}} \mathbf{P}_{\mathbf{0}}$ & 20746.89 & 0.998 & 0.032 & 0.208 & 0.001 \\
\hline${ }^{\mathbf{1}} \mathbf{D}_{\mathbf{2}}$ & 16977.93 & 1.001 & 0.021 & -0.085 & 0.000 \\
\hline
\end{tabular}

Table 7:- Computed values of Bonding parameters in (EtOH) Alcoholic medium

\begin{tabular}{|l|l|l|l|l|l|l|}
\hline S.N. & Energy Levels & $\mathbf{v}_{\mathbf{c}}\left(\mathbf{c m}^{-\mathbf{1}}\right)$ Obs & $\boldsymbol{\beta}$ & $\mathbf{b}^{\mathbf{1 / 2}}$ & $\mathbf{\delta} \%$ & $\boldsymbol{\eta}$ \\
\hline 1 & ${ }^{\mathbf{3}} \mathbf{P}_{\mathbf{2}}$ & 23337.22 & 1.035 & 0.132 & -3.382 & -0.017 \\
\hline 2 & ${ }^{\mathbf{3}} \mathbf{P}_{\mathbf{1}}$ & 21276.60 & 0.995 & 0.052 & 0.535 & 0.003 \\
\hline 3 & ${ }^{\mathbf{3}} \mathbf{P}_{\mathbf{0}}$ & 20661.16 & 0.994 & 0.056 & 0.624 & 0.003 \\
\hline 4 & ${ }^{1} \mathbf{D}_{\mathbf{2}}$ & 16863.41 & 0.994 & 0.054 & 0.594 & 0.003 \\
\hline
\end{tabular}

Table 8:- Computed value of energy interaction: Slater-Condon $\mathrm{F}_{\mathrm{k}}\left(\mathrm{cm}^{-1}\right)$,Spin-Orbit interaction Lande $\zeta_{4 \mathrm{f}}\left(\mathrm{cm}^{-1}\right)$ Racah $\mathrm{E}_{\mathrm{k}}\left(\mathrm{cm}^{-1}\right)$ perameters and Hydrogenic Ratio $\left(\mathrm{F}_{4} / \mathrm{F}_{2}\right),\left(\mathrm{F}_{6} / \mathrm{F}_{2}\right)$ and $\left(\mathrm{E}_{1} / \mathrm{E}_{3}\right),\left(\mathrm{E}_{2} / \mathrm{E}_{3}\right)$ of $\operatorname{Pr}(\mathrm{III})-8 \mathrm{HQ}$ Complexes in Alcoholic and micellar medium.

\begin{tabular}{|l|l|l|l|l|l|}
\hline \multicolumn{2}{|l|}{ Complex } & Pr(III)-8HQ & Pr(III)-8HQ & Pr(III)-8HQ & Pr(III)-8HQ \\
\hline S.N. & Parameters & $(\mathbf{E t O H )}$ & $\mathbf{( T X - 1 0 0 )}$ & $(\mathbf{H T A B})$ & (SDS) \\
\hline 1 & $\mathrm{E}_{1}$ & 4421.05 & 4456.68 & 4454.50 & 4440.42 \\
\hline 2 & $\mathrm{E}_{2}$ & 23.13 & 23.31 & 23.30 & 23.23 \\
\hline 3 & $\mathrm{E}_{3}$ & 446.99 & 450.59 & 450.37 & 448.95 \\
\hline 4 & $\mathrm{~F}_{2}$ & 301.12 & 303.55 & 303.40 & 302.44 \\
\hline 5 & $\mathrm{~F}_{4}$ & 373.06 & 349.53 & 443.67 & 323.12 \\
\hline 6 & $\mathrm{~F}_{6}$ & 26.57 & 25.04 & 31.35 & 23.24 \\
\hline 7 & $\zeta_{4 f}$ & 1184.83 & 1144.71 & 1262.39 & 1129.75 \\
\hline 8 & $\% \mathrm{r} \zeta_{4 f}$ & -64.45 & -58.85 & -73.46 & -62.59 \\
\hline 9 & $\% \mathrm{r} \mathrm{F}_{2}$ & 1.81 & 1.01 & 0.98 & 0.21 \\
\hline 10 & $\mathrm{~F}_{4} / \mathrm{F}_{2}$ & 1.239 & 1.151 & 1.462 & 1.068 \\
\hline 11 & $\mathrm{~F}_{6} / \mathrm{F}_{2}$ & 0.088 & 0.082 & 0.103 & 0.077 \\
\hline 12 & $\mathrm{E}_{1} / \mathrm{E}_{3}$ & 9.891 & 9.891 & 9.891 & 9.891 \\
\hline 13 & $\mathrm{E}_{2} / \mathrm{E}_{3}$ & 0.052 & 0.005 & 0.052 & 0.052 \\
\hline
\end{tabular}

Table 9:- Biological Investigation of Pr (III)-8HQ Complexe Against Bascillus Subtilis, Escherichia coli, Staphylococcus aureus.

\begin{tabular}{|l|l|l|}
\hline S.N. & complexes & Zone of inhibition (in mm) \\
\cline { 3 - 3 } & & $100 \mathrm{ppm}$ \\
\hline 1. & $\operatorname{Pr}(\mathrm{III})-$ - 8HQ Bascillus Subtilis & 35 \\
\hline 2. & $\operatorname{Pr}(\mathrm{III})-8 \mathrm{HQ}$ Escherichia coli & 8 \\
\hline 3. & $\operatorname{Pr}(\mathrm{III})-$ 8HQ Staphylococcus aureus & 40 \\
\hline
\end{tabular}




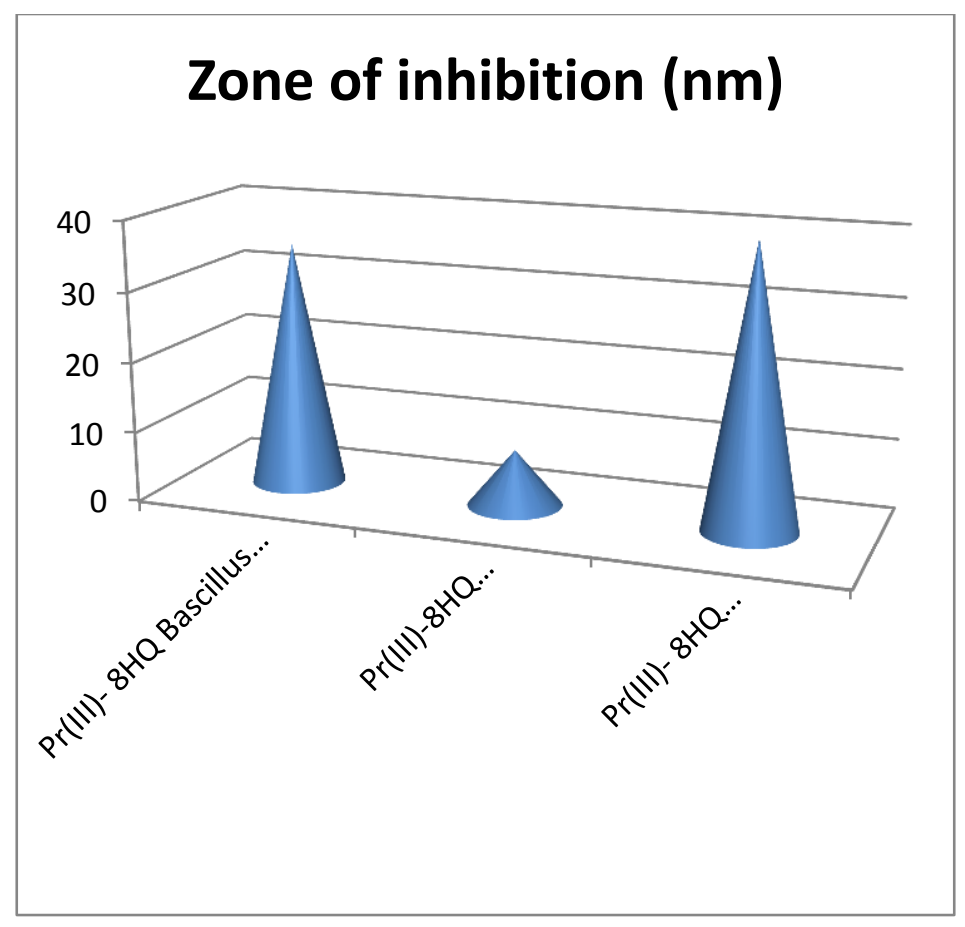

\section{Result and Discussion:-}

The normal and dervative electronic spectrum of $\operatorname{Pr}(\mathrm{III})$ ion and Pr (III)-8HQ complex in different solvent in UVvisible regions are shown in Fig 1-2. The observed value of oscillator strength for $\operatorname{Pr}^{3+}$ complex along with their calculated value has been show in table-1 The value of $\mathrm{T}_{2}, \mathrm{~T}_{4}$ and $\mathrm{T}_{6}$ parameter was computed using Judd-Ofelt relation by partial multiple regression method for Pr (III)-complexes (Table-2 ). Comparative absorption spectra of Pr (III)-complexes in alcoholic and micellar medium (Fig-1) clearly show a significant enhancement in the oscillator strength and intensity parameter $\mathrm{T}_{2}, \mathrm{~T}_{4}$ and $\mathrm{T}_{6}$. It is observed that all three Judd-Ofelt parameters $\left(\mathrm{T}_{2}, \mathrm{~T}_{4}, \mathrm{~T}_{6}\right)$ have positive values. The reason for $\mathrm{T}_{2}$ being negative for $\operatorname{Pr}$ (III)-8HQ in miceller medium has been attributed to f-d mixing. A similar conclusion was earlier made by Reisfeld(17).The wave numbers of the observed bands along with their assignments are presented in Table 3. Using the partial derivatives (9-11) for the $\operatorname{Pr}^{3+}$ ions and the calculated partial derivatives of the $\operatorname{Pr}^{3+}$ ion, the Racah $\left(\mathrm{E}^{1}, \mathrm{E}^{2}, \mathrm{E}^{3}\right)$, spin-orbit $\left(\zeta_{4 \mathrm{f}}\right)$ and the configuration interaction parameters were determined using the least squares fit method. They are presented in Table 8. The band positions have been calculated with these parameters. The rms deviations are reasonable. The intensities of the bands were measured only for the clear bands (15). The Judd-Ofelt intensity parameters were evaluated (Table 1) from the measured intensities of the absorption bands and the squared reduced matrix elements determined by the intermediate coupling scheme (11) The results are presented in Table 3.Derivative spectra would sometimes be helpful in resolving closely lying levels. it is very interesting to note that four bands ${ }_{3} \mathrm{P}^{2},{ }_{3} \mathrm{P}^{1},{ }_{3} \mathrm{P}^{0}$ and ${ }_{1} \mathrm{D}^{2}$. Each found split into two in the derivative spectrum shown in Fig. 2.However in all the complexes in to two components each. Although 3P2 have one additional component in TX -100 miceller medium and 3P1 have additional component in HTAB and in SDS miceller medium. A significant change in the oscillator strength of $\mathrm{f}-\mathrm{f}$ transition ( ie. ${ }_{3} \mathrm{H}^{4} \rightarrow{ }_{3} \mathrm{P}^{2}$ ) hypersensitive transitions(12). for Pr (III) ion have been observed in alcoholic and micellar medium has clearly reveled that a significant enhancement in the oscillator strength of f-f transition is observed Structure activity relationship for Pr (III)-8HQ system following results were obtained as Staphylococcus aureus $>\operatorname{Pr}(\mathrm{III})-$ 8HQ Bascillus Subtilis >Pr(III)-8HQ Escherichia coli

\section{References:-}

1. Wilkinson G, Gillard R and Mc J. Cleverty, Comprehensive Coor. Chem Pergamon Press Oxford, Chapter 39. (1987).

2. Misra S.N. and M. Indira Devi. The synthesis and determination of the octacoordinated structure of Pr (III)and $N d(I I 1)$ complexes with $\beta$-diketones and diols in non aqueous solutions: evidence of some participation of $\pi$ electron density of diols with Pr(III) and Nd(II1) in complexation. Spectrochim. Acta A. (53) 1941-1946 (1997).

3. Wybourne B G. Spectroscopic Properties of Rare Earth. Inter Conference. New York (1955). 
4. Hufner S. Optical Spectra of Transparent Rare Earth Compounds. Academic Press, New York, (1978).

5. Mishr S N, Joshi G K and Bhutra M P, Indian J. Chem., 21A(1982)278.

6. Mishra S N and Joshi G K, Indian J. of Pure and Applied Chemistry, 19(3) (1981)279.

7. Judd B R, Phys. Rev., 127(1962)750.

8. Ofelt G S, J. Chem. Phys., 37(1962)511.

9. Lakshman S. V. J. and Suresh Kumar A.. J. Non-Crvst. Solids 85, 162 (1986).

10. Lakshman S. V. J. and Jayasankar C. K., Spectrochim. Acta. A 48, 642 (1982). 16

11. Lakshman S. V. J. and Jayasankar C. K., Proc. Indian Natn. Acad. A 48, 642 (1982).

12. Jatolia S.N, Bhandari H.S, Bhojak N, Int. A. R. J.Sc. Eng.Tech., 1, 4(2014)201

13. Carnall W T, Fields P R and K Rajnak, J. Chem. Phys., 49 (1968)4424.

14. Carnall W T, Fields M H and Wybourn B C, J.Chem.Phys., $42(11)(1965) 3797$.

15. Wybourn W G, Spectroscopic properties of rare earth, Interscience publishers, New York, (1965).

16. Wong E Y, J. Chem. Phys., 35(1961)544.

17. R. Reisfeld, Structure and Bonding, 22 (1975) 123. 